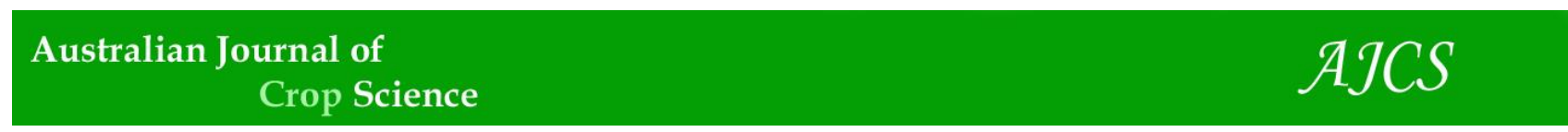

AJCS 13(09):1561-1565 (2019)

ISSN:1835-2707

doi: 10.21475/ajcs.19.13.09.p2031

\title{
New morphological key using male prothoracic leg characters to identify Helicoverpa (Lepidoptera: Noctuidae) species
}

\author{
Clerison Regis Perini ${ }^{1 *}$, Andres O. Angulo ${ }^{2}$, Tania Sonia Olivares ${ }^{2}$, Jonas Andre Arnemann ${ }^{1}$, Jerson \\ Vanderlei Carus Guedes ${ }^{1}$
}

\author{
${ }^{1}$ Federal University of Santa Maria, 1000 Roraima Av, 97105900, Santa Maria, Rio Grande do Sul, Brazil \\ ${ }^{2}$ University of Concepción, Concepción, Casilla 160-C, Concepción, Chile
}

\section{*Corresponding author: periniagro@gmail.com}

\begin{abstract}
Since invasion of Helicoverpa armigera (Hübner) in South America, identification of Helicoverpa species became essential for Integrated Pest Management (IPM). Thus, we worked out on a pictorial key to identify tree important Helicoverpa species that occur in the Southern Cone of America, using new morphological characters from the prothoracic legs. Adult male and female of Helicoverpa zea (Boddie), H. armigera, and Helicoverpa gelotopoeon (Dyar) were used for identification. Prothoracic legs from moths were removed and images were taken (magnification of 25X) with scales and specialized scales. In addition, images (magnification of 50X) of prothoracic legs were used to measure the foretibia and epiphysis. The results showed that measurable characters were more reliable and accurate on male moths than female moths. For this reason, we will show only detailed results of male moths. Foretibia of $\mathrm{H}$. zea were longer than $\mathrm{H}$. gelotopoeon, but shorter than $\mathrm{H}$. armigera. This size is visible with or without scales and specialized scales on males. Here, we show a first detailed description of protibial epiphysis. H. armigera has the longest epiphysis with fore margin pointed and with bristles terminating before the end of epiphysis. This illustrated pictorial key shown some first detailed descriptions of prothoracic legs. These characters are useful on integrated pest management programs of many crops to identify male representatives of Helicoverpa, which are captured on pheromone traps.
\end{abstract}

Keywords: foretibia, Helicoverpa sp., integrated pest management, pictorial key, protibial epiphysis, taxonomy.

Abbreviations: IPM_Integrated Pest Management; $\mathrm{KOH}_{-}$potassium hydroxide; $\mathrm{COI}$ _Cytochrome oxidase I; Cyt b_cytochrome b.

\section{Introduction}

Heliothinae (Noctuidae) caterpillars are the most significant pests world wide due to their polyphagous feeding habits that allow them to forage on both fruits and flowers, resulting in severe economic damage to many fibers, grain and vegetables crops. The Heliothinae family includes the genus Helicoverpa Hardwick and Heliothis Ochsenheimer, which have some of the most destructive agricultural species. The genus of Helicoverpa was described by Hardwick (1965), who recognized that species related to the Old World bollworm Helicoverpa armigera (Hübner, 1808) (Lepidoptera: Noctuidae) and the corn earworm $\mathrm{H}$. zea (Boddie, 1850) (Lepidoptera: Noctuidae) do not belong to Heliothis Ochsenheimer. Therefore, they constituted a separate monophyletic group and described 17 species in the new genus Helicoverpa Hardwick, including the Old World bollworm and the corn earworm. Basically, species of Helicoverpa differ from species of Heliothis in the structure of both male and female genitalia and in the presence of specialized scales on underside of forefemur of male, which are absent on Heliothis (Hardwick, 1965).

H. gelotopoeon (Dyar 1921) (Lepidoptera: Noctuidae), $H$. $z e a$, and $H$. armigera are the main species of Helicoverpa Hardwick in the Southern Cone of America. These species injure many vegetables, fruits, fibers and grains crops in Argentina, Brazil, Chile, Paraguay and Uruguay. Overall, farmers in these countries have high production costs to control Helicoverpa species. H. gelotopoeon is the main pest of many crops in Argentina (Cordo et al., 2004), Brazil, Chile, Paraguay, and Uruguay (Todd, 1955). H. zea is reported to be an important pest in corn and occurs in Brazil (Silva and Lima, 1968), Chile (Angulo et al., 2006), Argentina, Paraguay (Pastrana, 2004), and Uruguay (Biezanko et al., 1957). $H$. armigera was first reported causing damage on corn, soybean, and cotton in Brazil in 2013 (Czepak et al., 2013). They discovered recently that $H$. armigera was occurring in Brazil since 2008 (Sosa-Gómez et al., 2016). Even more, $H$. armigera was reported in Paraguay (Arnemann et al., 2016), Argentina (Murúa et al., 2014), and Uruguay (Castiglioni et al., 2016). However, it has not been reported in Chile yet.

From these three Heliothinae species, $H$. armigera seems to have a major importance worldwide in response to its economic losses of US\$ 5 billion annually (Lammers and MacLeod, 2007). The damage of this species in soybeans, for example, causes high yield losses (Stacke et al., 2018) and an elevated control cost with most of chemical insecticides, resulting in a low net income to soybeans producers (Perini 
et al., 2016). Suitable identification of a pest species is one of the management strategies to support a decision and usage of pest control tactics on an Integrated Pest Management (IPM) (Kogan, 1998). Identification of Helicoverpa species is determined by internal morphology on male and female genitalia supported by taxonomic keys, or molecular markers (COI and Cyt b). Currently, morphological identification is determined using the key of Hardwick (1965). Recently, a clarification in the differentiation of adult male genitalia of $H$. zea and $H$. armigera was reported (Pogue, 2004). These characters of genitalia described on male and female moths are specific and most used to identify Helicoverpa species.

Taxonomy identification of Helicoverpa became frequently from researchers and farmers since the invasion of $\mathrm{H}$. armigera in some countries of the South Cone of America. Both identification methodologies (morphological or molecular markers) are complex, time consuming, have high cost with equipment and reagents, and are made exclusively in laboratory. Therefore, the objective of this study is to present pictorial key using new characters, which had not been well-explored yet.

\section{Results}

The findings of this study are useful to assist pest monitoring regarding the taxonomy, which is a crucial first step in IPM programs. Both characters analyzed from the foreleg (tibia and epiphysis) show significant differences across male Helicoverpa in both size and shape (Fig. 1) (Fig. 2). $H$. armigera and $H$. zea are very similar in external morphological characters. Thus, description of foretibia and protibial epiphysis provides useful alternatives for male genitalia identification of Helicoverpa species. On female specimens these characters showed intraspecific variation with inconsistent measured values (data not shown) on tibia and epiphysis. It demonstrates no accuracy method to identify these Helicoverpa species using female moths. For this reason, the results will be presented and discussed only from male moth measurements.

\section{Characterization of foretibia}

H. gelotopoeon has the smallest foretibia, wheras $H$. armigera foretibia are the largest (Table 1). The difference in foretibia length from $\mathrm{H}$. armigera to $\mathrm{H}$. zea is approximately $0.2 \mathrm{~mm}$. This foretibia characteristic is more visible after removal of specialized scales using $\mathrm{KOH}$ solution. Thus, to identify male moth species accurately using this character is important to have a practical training with samples of prothoracic legs from known species and/or associate with protibial epiphysis character. The spiniform on $H$. gelotopoeon setae is long and visible without removal of the scales and specialized scales from foretibia. H. armigera and $H$. zea do not have the spiniform setae visible.

\section{Characterization of protibial epiphysis}

Differences on protibial epiphysis that enable identification can be viewed only after removal of scales and specialized scales from the foretibia and epiphysis. $H$. gelotopoeon has the shortest epiphysis $(0.69 \pm 0.036 \mathrm{~mm})$ (Table 1$)$ and the fore margin is rounded with bristles terminating in the end, which differentiate it from the $\mathrm{H}$. zea and $\mathrm{H}$. armigera (Fig 2.a.). Epiphysis size of $H$. zea is intermediate among species $(0.88 \pm 0.042 \mathrm{~mm})$ with fore margin pointed and bristles terminate right before the end (Fig 2.b.). H. armigera has the longest epiphysis $(0.95 \pm 0.114 \mathrm{~mm})$ with the fore margin pointed and bristles terminating before the end (Fig 2.c.). Bristles termination in $\mathrm{H}$. zea and $\mathrm{H}$. armigera are quite similar, but very different from $H$. gelotopoeon. It is a character that should be investigated in other Helicoverpa species.

\section{Key description}

We present a key description of prothoracic leg characters on male moth species of Helicoverpa that are important in the Southern Cone of America. This key is supported by images that provide detailed differences between species. 1- Foretibia small and thin $(1.27 \pm 0.060 \mathrm{~mm})$ with stout and prominent spiniform setae; outer margin of pretibial with four to five robust spiniform setae (in addition to apical spiniform setae) visible with the scales and specialized scales; epiphysis is shortest $(0.67 \pm 0.036 \mathrm{~mm})$ and fore margin is pointed with bristles terminating in the end of epiphysis (Fig. 1A-D and 2A) ......... Helicoverpa gelotopoeon. 2- Spiniform setae on the outer margin of foretibia, not visible with scales and specialized scales, only the two apical spiniform setae are visible 3.

$3^{\prime}(2)$ - Foretibia longer than $H$. gelotopoeon and shorter than $H$. armigera $(1.64 \pm 0.076 \mathrm{~mm})$; epiphysis insertion nearest to the distal margin of foretibia $(0.68 \pm 0.047 \mathrm{~mm})$ compared to $H$. armigera; epiphysis with an average length of $0.88 \pm 0.042$ $\mathrm{mm}$ and the fore margin is pointed and with bristles terminating right before the end of the pointed epiphysis (Figs. 1B-E and 2B) ...................................... Helicoverpa zea.

$3^{\prime \prime}(2)$ - Foretibia longer than $H$. gelotopoeon and $H$. zea $(1.84 \pm 0.025 \mathrm{~mm})$; insertion of epiphysis more distally from the distal margin of foretibia compared to $H$. zea $(0.82 \pm 0.084 \mathrm{~mm})$; epiphysis with average length of $0.95 \pm 0.114 \mathrm{~mm}$ and fore margin is pointed with bristles terminating before the end of the pointed epiphysis (Figs. $1 \mathrm{C}-\mathrm{F}$ and $2 \mathrm{C}$ ) ..................................... Helicoverpa armigera.

\section{Discussion}

Regarding the importance of correct identification of Helicoverpa species, this pictorial key can be used on IPM program of fibers, grain, and vegetables crops. The leg character has never been deeply described and here we show all differences between these three main Helicoverpa species. The number of spiniform on the outer margin of the foretibia varied on specimens within species. Todd (1955) demonstrated that $H$. gelotopoeon can be safely identified with three or more spines on the outer margin of the foretibia, which distinguish specimens that have less than three spiniform setae. In the present study $H$. gelotopoeon ranged from four to six spiniform on the outer margin of the 
Table 1. Morphological characters on prothoracic legs that differentiate Helicoverpa species.

\begin{tabular}{|c|c|c|c|c|c|c|c|c|}
\hline & & H. gelotopoeon & $t^{1}$ & H. zea & $\mathrm{t}$ & H. armigera & $\mathrm{t}$ & $\mathrm{CV}^{4}{ }^{4}$ \\
\hline \multirow[t]{2}{*}{ Foretibia } & Length & $1.27 \mathrm{~mm}( \pm 0.060)$ & $\mathrm{C}$ & $1.64 \mathrm{~mm}( \pm 0.076)$ & $B$ & $1.84 \mathrm{~mm}( \pm 0.025)$ & $A$ & 4.01 \\
\hline & Length & $0.69 \mathrm{~mm}( \pm 0.036)$ & $\mathrm{B}$ & $0.88 \mathrm{~mm}( \pm 0.042)$ & A & $0.95 \mathrm{~mm}( \pm 0.114)$ & $A$ & 9.52 \\
\hline \multirow[t]{2}{*}{ Epiphysis protibial } & Fore margin & $\begin{array}{l}\text { Rounded / bristles until } \\
\text { the end }\end{array}$ & & $\begin{array}{l}\text { Pointed / bristles } \\
\text { right before the } \\
\text { end }\end{array}$ & & $\begin{array}{l}\text { Pointed / bristles } \\
\text { before the end }\end{array}$ & & - \\
\hline & Insertion $^{2}$ & $0.54 \mathrm{~mm}( \pm 0.035)$ & $\mathrm{C}$ & $0.68 \mathrm{~mm}( \pm 0.047)$ & B & $0.82 \mathrm{~mm}( \pm 0.084)$ & $A$ & 9.55 \\
\hline Spiniform setae & Visible $^{3}$ & yes & & no & & no & & - \\
\hline Figure & & 1a; 1d; 2a & & $1 b ; 1 e ; 2 b$ & & 1c; $1 \mathrm{f} ; 2 \mathrm{c}$ & & - \\
\hline
\end{tabular}

Fig 1. Details of male moths on prothoracic legs with (magnification of $25 \mathrm{X}-\mathrm{a}, \mathrm{b}$ and $\mathrm{c}$ ) and without (magnification of $50 \mathrm{X}-\mathrm{d}$, e and f) scales and specialized scales: Helicoverpa gelotopoeon (a; d), Helicoverpa zea (b; e) and Helicoverpa armigera (c; f).

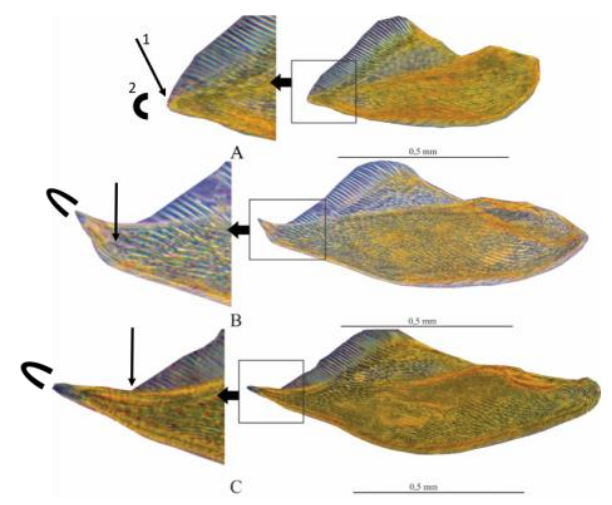

Fig 2. Details of protibial epiphysis of Helicoverpa gelotopoeon (a), Helicoverpa zea (b) and Helicoverpa armigera (c). 1: Arrows showing bristles termination at the fore margin of epiphysis for $H$. gelotopoeon and H. zea. 2: Arc showing the shape of fore margin: rounded for $H$. gelotopoeon and pointed for $H$. zea and $H$. armigera.

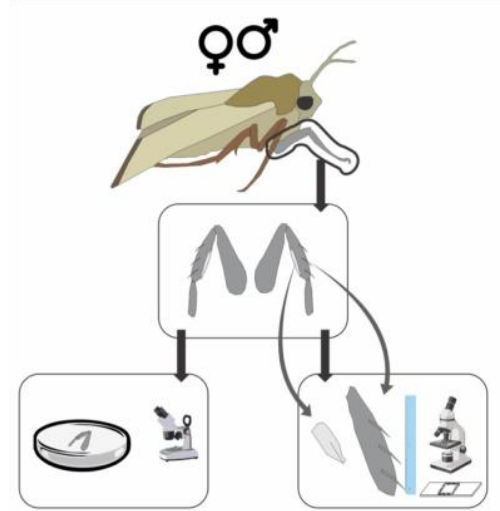

Fig 3. The workflow used to characterize the foretibia and protibial epiphysis. Removal of forelegs, analysis on stereomicroscope and measurements on the inverted microscope. 
foretibia, $H$. zea ranged from two to three and $H$. armigera have two to four spiniform. Thus, we suggest that the number of spiniform on the outer margin of the foretibia is not a morphological character that can distinguish species safely. However, the size and shape of spiniform setae is discriminatory (Hardwick, 1965) and $H$. gelotopoeon have a robust and prominent spiniform setae on the outer margin of the foretibia (Pogue, 2013), that can be seen without a hand magnifier.

Another morphological character investigated deeply was the epiphysis protibial with measurements and image analyses. Protibial epiphysis was never explored in a taxonomic key of Helicoverpa species and here we show a detailed description of some slight differences. The function of epiphysis is to clean antennas when moths are flying or in repose (Callahan and Carlysle, 1971). For this reason, there is a longitudinal cavity on epiphysis to receive the antenna and a row of bristles, which we believed that helps to clean when the antenna passes through the cavity.

This pictorial key describes the external morphological characters and provides new characters to identify Helicoverpa species. $H$. gelotopoeon has the smallest foretibia with spiniform visible under scales and specialized scales and protibial epiphysis with fore margin pointed and bristles terminating in the end. We believe that this character on $H$. gelotopoeon is more useful and more accurate than wing characteristics. Male moths of $H$. zea and $H$. armigera can be distinguished mainly by the size of foretibia, while the epiphysis is slightly similar between both species.

\section{Materials and methods}

\section{Insect species and its identification}

Insect species of $H$. gelotopoeon, $H$. zea and $H$. armigera were obtained from the colony of the Integrated Pest Management Laboratory (LabMIP), at Federal University of Santa Maria. Insect colonies were reared on artificial diet adapted from Greene et al. (1976) in a room with controlled conditions of $25 \pm 2^{\circ} \mathrm{C}, 70 \pm 10 \% \mathrm{RH}$, and 14 hours of photophase. At the end of insect life cycle, dead moths were used to perform this study.

Primarily, Helicoverpa species were accurately identified. For this. The abdomens were removed, placed in eppendorf tubes with $\mathrm{KOH}(10 \%)$ solution and kept for 60 minutes at 65으 temperature (adapted from Brambila, 2009). Specimens were identified with male and female genitalia using the key of Hardwick (1965) and the description of Pogue (2004). Voucher specimens were deposited at LabMIP. Male and female specimens $(8 \propto$ and $6 \hat{0}$ of each species) of $H$. gelotopoeon, $H$. zea and $H$. armigera were used to characterize morfologically the prothoracic legs.

\section{Characterization of prothoracic legs}

Treatments were arranged in a completely randomized design with three species of $H$. gelotopoeon, $H$. zea and $H$. armigera and eight replications for male moths and six for female moths. All procedure workflow explained below is illustrated in the Fig 3. Prothoracic legs were carefully removed and examined to describe characters of foretibia and epiphysis. One of the prothoracic leg was analyzed and photographed on the stereomicroscope (magnification 25X) with a digital camera (Sony, Cyber shot W830). Shape and size (length and width) of foretibia and spiniforms were analyzed in these images. The other prothoracic leg was prepared in $\mathrm{KOH}(10 \%)$ solution and kept for 24 hours at room temperature to remove the scales and specialized scales. These prothoracic legs, as well as the epiphysis protibial were placed on slides and images were taken with an inverted microscope Axio Vert.A1 (Zeizz, Jena, Germany) at 50X magnification. The ZEN ${ }^{\circ}$ software (Zeizz, Jena, Germany) integrated on the inverted microscope was used to measure foretibia and epiphysis lengths accurately, distance from the epiphysis insertion to distal margin of foretibia, and width of foretibia.

\section{Statistical analysis}

Statistical analysis was accomplished using SISVAR (Ferreira, 2011). Measurement data of foretibia and protibial epiphysis were analyzed with ANOVA and means were separated using Scott-Knott grouping test $(P \leq 0.05)$.

\section{Key description}

Description of taxonomic key was based on the morphological characters of prothoracic legs of male moths to assist identification of the three species of Helicoverpa. For each species morphological characters are presented observed and measured on foretibia and protibial epiphysis. Additionally, we present detailed imagens for the pictorial key to support key description and the morphological identification of male moths.

\section{Conclusion}

In conclusion, the present study provides information on understanding differences of tibia and epiphysis of forelegs on male moths. Female sex pheromone trap is the most used to monitor Helicoverpa species on crop fields. Thus, identification of male specimens captured on these traps can be done with this illustrated key distinguishing among these closely related species. Even more, it can support identification in the field and in the laboratory with methods more complex, such as, genitalia dissection or molecular techniques.

\section{Acknowledgments}

The authors would like to thank the scholarship granted by CAPES to first author.

\section{References}

Angulo AO, Olivares TS, Weigert TH (2006) Estados inmaduros de lepidópteros nóctuidos de importancia económica agrícola y forestal en Chile (Lepidoptera: Noctuidae), 2nd edn. Universidad de Concepción, Concepción. 154p.

Arnemann JA, James WJ, Walsh TK, Guedes JVC, Smagghe G, Castiglioni E, Tay WT (2016) Mitochondrial DNA COI characterization of Helicoverpa armigera (Lepidoptera: Noctuidae) from Paraguay and Uruguay. Gen Mol Res. 15:1-8. 
Biezanko CM, Ruffinelli A, Carbonell CS (1957) Lepidoptera del Uruguay: lista anotada de especies. Rev Fac Agro. 46:3149.

Brambila J (2009) Instructions for dissecting male genitalia of Helicoverpa (Lepidoptera: Noctuidae) to separate $\mathrm{H}$. zea from $H$. armigera. Available online at: https://www.aphis.usda.gov/plant_health/plant_pest_info /owb/downloads/owb-screeningaids 2.pdf (Accessed 20 June 2014).

Callahan OS, Carlysle TC (1971) A Function of the epiphysis on the foreleg of the corn earworm moth, Heliothis zea. An Entom Soc America. 64(1):309-311.

Castiglioni E, Perini CR, Chiaravalle W, Arnemann JA, Ugalde G, Guedes JVC (2016) Primer registro de ocurrencia de Helicoverpa armigera (Hübner, 1808) (Lepidoptera: Noctuidae) en soja, en Uruguay. Agro Urug. 20:31-35.

Cordo HA, Logarzo G, Braun K, Di lorio O (2004) Catálogo de insectos fitófagos de la Argentina y sus plantas asociadas. Sociedad Entomológica Argentina, Buenos Aires. 734 pp.

Czepak C, Albernaz KC, Vivan LM, Guimarães HO, Carvalhais $T$ (2013) First reported occurrence of Helicoverpa armigera (Hübner) (Lepidoptera: Noctuidae) in Brazil. Pes Agrop Trop. 43:110-113.

Ferreira DF (2011) Sisvar: a computer statistical analysis system. Ciência e Agrotec. 35(6):1039-1042.

Greene GL, Leppla NC, Dickerson WA (1976) Velvetbean caterpillar: a rearing procedure and artificial medium. J Econ Entomol. 69:488-497.

Hardwick D (1965) The corn earworm complex. Mem Ento Soc Canada. 97:5-247.

Kogan M (1998) Integrated Pest Management: historical perspectives and contemporary developments. A Rev Entomol. 43:243-70.

Lammers JW, Macleod A (2007) Report of a pest risk analysis: Helicoverpa armigera (Hübner, 1808). 18p. Available online at: http://www.fera.defra.gov.uk/plants/plantHealth/pestsDis eases/documents/helicoverpa.pdf

September 2015).

Murúa MG, Scalora FS, Navarro FR, Cazado LE, Casmuz A, Villagrán ME, Lobos E, Gastaminza G (2014) First record of Helicoverpa armigera (Lepidoptera: Noctuidae) in Argentina. Flor Entomol. 97:854-856.

Pastrana JA (2004) Los lepidopteros argentinos: sus plantas hospedadoras y otros substratos alimenticios. Sociedade Entomológica Argentina, Buenos Aires. 334 p.

Perini CR, Arnemann JA, Melo AA, Pes MP, Valmorbida I, Beche M, Guedes JVC (2016) How to control Helicoverpa armigera on soybean in Brazil? What we have learned since its detection. African J Agri Res. 11:1426-1432.

Pogue MG (2004) A new synonym of Helicoverpa zea (Boddie) and differentiation of adult males of $H$. zea and $H$. armigera (Hübner) (Lepidoptera: Noctuidae: Heliothinae). Ann Ent Soc of America. 97:1222-1226.

Pogue MG (2013) Revised status of Chloridea Duncan and (Westwood), 1841, for the Heliothis virescens species group (Lepidoptera: Noctuidae: Heliothinae) based on morphology and three genes. Syst Entomol. 38:523-542.

Silva AGA, Lima AMC (1968) Quarto catálogo dos insetos que vivem nas plantas do Brasil: seus parasitas e predadores. Departamento de Defesa e Inspeção Agropecuária. Rio de Janeiro. $422 \mathrm{p}$.

Stacke RF, Arnemann JA, Rogers J, Stacke RS, Strahl TT, Perini CR, Dossin MF, Pozebon H, Cavallin LA, Guedes JVC (2018) Damage assessment of Helicoverpa armigera (Lepidoptera: Noctuidae) in soybean reproductive stages. Crop Protection. 112:10-17.

Sosa-Gómez DR, Specht A, Paula-Moraes SV, Lopes-Lima A, Yano SAC, Micheli A, Morais EGF, Gallo P, Pereira PRVS, Salvadori JR, Botton M, Zenker MM, Azevedo-Filho WS (2016) Timeline and geographical distribution of Helicoverpa armigera (Hübner) (Lepidoptera, Noctuidae: Heliothinae) in Brazil. Rev Bras Entomol. 60:101-104.

Todd EL (1955) The distribution and nomenclature of the corn earworm. J Econ Entomol. 48:600-603. 